\title{
Surface temperature trends in Russia over the past five centuries reconstructed from borehole temperatures
}

\author{
Henry N. Pollack, ${ }^{1}$ Dmitriy Y. Demezhko, ${ }^{2}$ Albert D. Duchkov, ${ }^{3}$ Inessa V. Golovanova, ${ }^{4}$ \\ Shaopeng Huang, ${ }^{1}$ Vladislav A. Shchapov, ${ }^{2}$ and Jason E. Smerdon ${ }^{5}$ \\ Received 14 August 2002; revised 4 December 2002; accepted 19 December 2002; published 2 April 2003.
}

[1] We analyze borehole temperature logs from 101 sites in Russia and nearby areas to reconstruct the ground surface temperature history (GSTH) over the past five centuries. The data are drawn principally from three regions: the Urals, southwest Siberia, and northeast Siberia. We derive GSTHs for each region individually, and a composite "all-Russia" GSTH from the full ensemble of sites. The results show that over the past 500 years, the investigated areas have on average warmed $\sim 1 \mathrm{~K}$, with more than half of the warming occurring in the 20th century alone, and $70-80 \%$ in the 19th and 20th centuries taken together. The 16th through 18th centuries in the Urals and southwest Siberia were on average $0.1-0.2 \mathrm{~K}$ cooler than at the beginning of the 19th century, but northeast Siberia was more moderate in the 16th through 19th centuries, relative to the present-day, than the Urals or southwest Siberia. A wide variety of instrumental, proxy, and indirect evidence support these geothermal results. INDEX TERMS: 3344 Meteorology and Atmospheric Dynamics: Paleoclimatology; 8130 Tectonophysics: Evolution of the Earth: Heat generation and transport; 9320 Information Related to Geographic Region: Asia;

KEYWORDS: Russia, borehole temperatures, climate reconstruction

Citation: Pollack, H. N., D. Y. Demezhko, A. D. Duchkov, I. V. Golovanova, S. Huang, V. A. Shchapov, and J. E. Smerdon, Surface temperature trends in Russia over the past five centuries reconstructed from borehole temperatures, J. Geophys. Res., 108(B4), 2180, doi:10.1029/2002JB002154, 2003.

\section{Introduction}

[2] The ongoing international debate about how humans affect Earth's climate has promoted many investigations of climate variability over timescales that span both the industrial and preindustrial periods. Here we report a five-century reconstruction of the surface temperature history over a large area of Russia and nearby regions, derived from subsurface temperature profiles obtained in boreholes.

[3] The interiors of the large Northern Hemisphere continents play a central role in the hemispheric and global climate system, in part by serving as conduits for cold dense polar air masses to travel to temperate latitudes relatively unimpeded. In particular the Siberian high-pressure anomaly is an important contributor to Northern Hemisphere climate variability during winter [Cohen et al., 2001]. Given the possibility, indeed the likelihood, that the global climate system has been anthropogenically perturbed in the 20th

\footnotetext{
${ }^{1}$ Department of Geological Sciences, University of Michigan, Ann Arbor, Michigan, USA.

${ }^{2}$ Institute of Geophysics, Russian Academy of Sciences, Ekaterinburg, Russia.

${ }^{3}$ Institute of Geophysics, Russian Academy of Sciences, Novosibirsk, Russia.

${ }^{4}$ Institute of Geology, Russian Academy of Sciences, Ufa, Russia.

${ }^{5}$ Applied Physics Program, University of Michigan, Ann Arbor, Michigan, USA.
}

Copyright 2003 by the American Geophysical Union. 0148-0227/03/2002JB002154\$09.00 century, the large continental interior of north Asia is unlikely to have escaped impact. The focus of this paper is on estimating the magnitude and extent of 20th century temperature changes in Russia, within the context of the temperature history at the ground surface over the last five centuries, as inferred from subsurface temperatures.

[4] The thermal regime of the outer few hundred meters of the Earth's continental crust is governed principally by two processes: the outward flow of heat from the planetary interior and downward propagating temperature perturbations arising from a temporally varying temperature at the land surface. Changes in the outward heat flux from the interior occur only on timescales of millions of years; thus in the context of climate changing on decadal, centennial, or millennial timescales, the outward flux and its subsurface temperature signature can be considered to be in a steady state. Therefore one important aspect of the borehole thermometry approach to climate reconstruction (see Pollack and Huang [2000] for a review) is to identify and separate the steady state subsurface temperature field from the more rapidly changing subsurface temperatures driven by climate-related temperature fluctuations at the surface.

[5] The borehole thermometry approach to climate reconstruction has both strengths and weaknesses. Unlike many climate proxies that require an empirical calibration to convert proxy measurements into temperature, borehole temperature profiles are acquired directly with modern well-calibrated thermometers. Additionally, many boreholes have been drilled into the Earth in a wide variety of 
locations for a multitude of purposes, and in principle offer the potential for wide geographic coverage. However, subsurface temperatures can reflect many factors other than a changing climate at the surface. Subsurface heterogeneity, both structural and stratigraphic, advective heat transfer by moving subsurface fluids, surface topography, and vegetation patterns: each can leave an imprint on subsurface temperatures that in some cases can mimic the signature of climate change. Thus one must be careful to exercise quality control measures in the selection of borehole profiles for analysis, and be cautious in their interpretation.

\section{Borehole Thermometry in Russia}

[6] The measurement of subsurface temperatures in Russia and the other republics of the former Soviet Union in the last half of the 20th century was focused principally on the determination of the heat flux from the Earth's interior. An understanding of the regional variability of this flux was important to an understanding of many phenomena, from global tectonics to the stability of permafrost and the thermal maturity of hydrocarbons in sedimentary basins. From the beginning of the International Heat Flow Commission in the early 1960s, Russians played a leading role in encouraging measurements of the terrestrial heat flux, and in establishing a worldwide database of such measurements. Seminal concepts in thermotectonics and the thermal evolution of the Earth were advanced by prominent Russian geophysicists [Polyak and Smirnov, 1968; Lubimova, 1958; Lubimova et al., 1965]. The number of heat flux measurements eventually catalogued in the former Soviet Union exceeded 1400 [Pollack et al., 1993]. It is principally from this large archive of heat flux boreholes that the data for the present investigation of recent climate in Russia have been selected.

[7] Of the many thousands of boreholes in which temperature logs have been taken, in Russia and elsewhere, only a small fraction prove suitable for climate reconstructions. This is because of the strict quality control measures that must be applied to data, before attempting an inversion to recover a ground surface temperature history. For a variety of reasons many boreholes that may have been satisfactory for determining the terrestrial heat flux (essentially the deeper, steady state component of a subsurface temperature profile) prove unsuitable for determining the transient component related to changing climate. For example, all commonly used inversion methodologies that recover a ground surface temperature history (GSTH) from a subsurface temperature profile are based on the theory of heat conduction, and thus boreholes that exhibit significant water flow, i.e., advective heat transfer, will be unsuitable. Similarly, because heat conduction is a diffusion process, a profile exhibiting sharp changes, rapid reversals or discontinuities in gradient, particularly at greater depths, has probably been affected by nonconductive behavior, and must be rejected for analysis. Boreholes that have penetrated permafrost at depth and encounter an active zone at the top or bottom of the permafrost have also been rejected for analysis because of the complications associated with ongoing phase changes and latent heat effects. However, boreholes in permafrost where the entire thermal regime

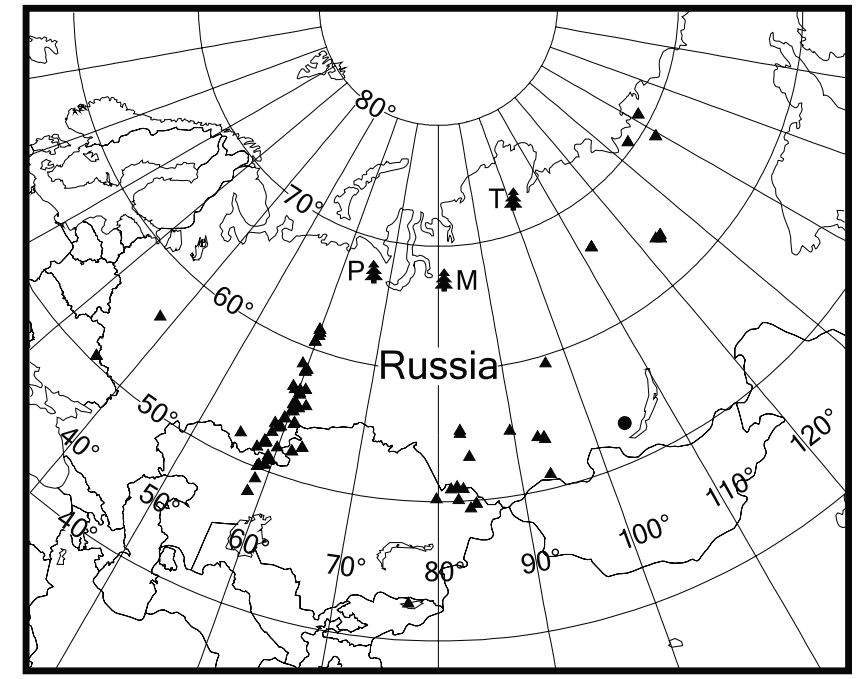

Figure 1. Site map showing locations (triangles) of the 101 boreholes that yielded temperature logs used for climate reconstructions. P, M, and T are sites of the Polar Urals, Mangazeja, and Taimyr dendrochronologies, respectively, from Esper et al. [2002]. The solid circle near Lake Baikal marks the site of the Irkutsk Observatory.

remains well below the freezing temperature can in principle provide subsurface temperature profiles suitable for inversion. Even with strict quality control criteria, sufficient numbers of suitable borehole logs have been identified across Russia to enable several regional climate investigations.

[8] Regional climate studies using borehole temperature data have already been presented for various parts of the Ural Mountains [Khachai et al., 1996; Demezhko, 2001; Stulc et al., 1997, 1998; Golovanova et al., 2001] both in Russia and adjacent Kazakhstan and in southwest Siberia [Duchkov and Sokolova, 1998; Sukhorukova and Duchkov, 1998; Duchkov et al., 2000]. Each team of investigators in these different regions decided which borehole profiles to analyze, utilized their own preferred inversion scheme, incorporated their personal approaches to smoothing and noise suppression, and selected their preferred parameterizations for the form of the ground surface temperature history. This diversity has made intercomparison of details of the regional results difficult. Here we reanalyze these regional data sets, along with many new data from other regions in Russia, applying a uniform quality control data filter and using a common data analysis scheme for the entire ensemble of borehole temperature profiles.

[9] Altogether we have selected 101 borehole temperature profiles for analysis. Their locations are shown in Figure 1, and the principal details of each are presented in Table 1. Many of these borehole profiles have been displayed in the earlier publications of the regional investigations [Stulc et al., 1997, 1998; Golovanova et al., 2001; Demezhko, 2001; Duchkov and Sokolova, 1998; Sukhorukova and Duchkov, 1998; Duchkov et al., 2000]. Although some boreholes were logged to depths greater than shown in Table 1, we have confined our attention to data from the upper $600 \mathrm{~m}$; all surface perturbations within the past 
Table 1. Principal Facts About the Boreholes Used for Climate Reconstructions

\begin{tabular}{|c|c|c|c|c|c|c|c|}
\hline $\begin{array}{l}\text { Index } \\
\text { Number }\end{array}$ & $\begin{array}{c}\text { Borehole } \\
\text { Identification }\end{array}$ & $\begin{array}{c}\text { Latitude, } \\
{ }^{\circ} \mathrm{N}\end{array}$ & $\begin{array}{c}\text { Longitude, } \\
{ }^{\circ} \mathrm{E}\end{array}$ & $\begin{array}{l}\text { Log } \\
\text { Year }\end{array}$ & 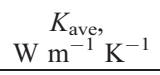 & $\begin{array}{c}\text { Depth } \\
\text { Range, } m\end{array}$ & $\begin{array}{c}\text { Number of } \\
\text { Measurements }\end{array}$ \\
\hline 1 & Mur-10-v & 50.50 & 35.50 & 1993 & & $80-400$ & 73 \\
\hline 2 & Pet-643 & 50.50 & 35.50 & 1993 & & $45-200$ & 76 \\
\hline 3 & Shi-635-g & 50.50 & 35.50 & 1993 & & $70-240$ & 69 \\
\hline 4 & Mitino & 56.00 & 38.00 & 1985 & & $50-280$ & 15 \\
\hline 5 & Orenburg-703 & 52.00 & 55.00 & 1990 & 2.50 & $20-465$ & 90 \\
\hline 6 & Mednogorsk-935 & 51.50 & 57.50 & 1977 & 1.83 & $60-600$ & 28 \\
\hline 7 & Argagan-2167 & 52.17 & 58.08 & 1978 & 2.15 & $25-450$ & 18 \\
\hline 8 & Makan-2431 & 52.00 & 58.25 & 1972 & 3.19 & $80-600$ & 27 \\
\hline 9 & Makan-3276 & 52.00 & 58.25 & 1973 & 2.94 & $20-340$ & 17 \\
\hline 10 & P-107 & 52.08 & 58.33 & 1976 & & $40-600$ & 57 \\
\hline 11 & Podolsk P-34 & 52.08 & 58.33 & 1973 & 2.73 & $20-600$ & 30 \\
\hline 12 & Krom Tau-191 & 50.17 & 58.42 & 1981 & 2.37 & $20-500$ & 26 \\
\hline 13 & Krom Тau-192 & 50.17 & 58.42 & 1976 & 2.37 & $20-600$ & 30 \\
\hline 14 & Krom Tau-216 & 50.17 & 58.42 & 1981 & 2.21 & $20-360$ & 18 \\
\hline 15 & Krom Tau-79 & 50.17 & 58.42 & 1981 & 1.95 & $30-600$ & 30 \\
\hline 16 & Tastybulak-45 & 48.17 & 58.42 & 1976 & 3.06 & $20-420$ & 21 \\
\hline 17 & Tastybulak-48 & 48.17 & 58.42 & 1976 & 2.57 & $20-480$ & 24 \\
\hline 18 & Krom Tau-639 & 50.33 & 58.50 & 1981 & 1.77 & $30-520$ & 25 \\
\hline 19 & Salavat-1790 & 53.67 & 58.50 & 1976 & 3.42 & $40-600$ & 29 \\
\hline 20 & North Khudolaz-184 & 52.95 & 58.55 & 1991 & 2.46 & $40-600$ & 57 \\
\hline 21 & Sarsaj-1 & 49.25 & 58.67 & 1976 & 2.47 & $40-400$ & 20 \\
\hline 22 & Bs-135 & 56.82 & 59.00 & 1979 & & $60-320$ & 14 \\
\hline 23 & 1701 & 53.50 & 59.08 & 1969 & 2.14 & $50-460$ & 22 \\
\hline 24 & 2066 & 53.42 & 59.08 & 1987 & 2.51 & $40-600$ & 29 \\
\hline 25 & Koktau-1124 & 50.50 & 59.08 & 1976 & 2.64 & $80-600$ & 27 \\
\hline 26 & Kyzyl Kibachi-2077 & 50.42 & 59.08 & 1976 & 2.50 & $40-580$ & 29 \\
\hline 27 & MDV-622 & 58.72 & 59.12 & 1997 & & $37-392$ & 53 \\
\hline 28 & Aschebutak-5107 & 51.17 & 59.17 & 1977 & 2.50 & $40-500$ & 24 \\
\hline 29 & $\mathrm{Mg}-3$ & 53.57 & 59.27 & 1987 & & $40-280$ & 25 \\
\hline 30 & N Alexandrinka-5937 & 53.58 & 59.33 & 1994 & 2.62 & $20-600$ & 59 \\
\hline 31 & Sar-2702 & 56.65 & 59.37 & 1977 & & $60-530$ & 48 \\
\hline 32 & North Uchali-1754 & 54.33 & 59.42 & 1993 & 2.74 & $30-600$ & 62 \\
\hline 33 & South Uchali-1703 & 54.25 & 59.50 & 1990 & 2.88 & $40-550$ & 53 \\
\hline 34 & Osennee- 4480 & 50.92 & 59.58 & 1976 & 2.63 & $30-600$ & 30 \\
\hline 35 & Ns-2016 & 60.68 & 59.72 & 1984 & & $80-570$ & 35 \\
\hline 36 & Ns-2017 & 60.68 & 59.72 & 1984 & & $30-600$ & 58 \\
\hline 37 & Ns-2021 & 60.68 & 59.72 & 1984 & & $30-470$ & 45 \\
\hline 38 & $2-\mathrm{s}-116$ & 61.67 & 59.77 & 1985 & & $70-360$ & 21 \\
\hline 39 & $2-s-117$ & 61.67 & 59.77 & 1985 & & $13-570$ & 47 \\
\hline 40 & $2-\mathrm{s}-139$ & 61.67 & 59.77 & 1985 & & $20-460$ & 44 \\
\hline 41 & 14 & 55.50 & 59.83 & 1975 & 2.83 & $40-600$ & 29 \\
\hline 42 & Aidyrlya-3879 & 52.00 & 59.83 & 1982 & 3.60 & $19-256$ & 12 \\
\hline 43 & KU-622 & 58.32 & 59.84 & 1977 & & $50-600$ & 56 \\
\hline 44 & VOL-0477 & 58.17 & 59.85 & 1977 & & $80-600$ & 27 \\
\hline 45 & VOL-1 & 58.17 & 59.85 & 1977 & & $100-600$ & 51 \\
\hline 46 & KU-649 & 58.32 & 59.87 & 1977 & & $90-600$ & 52 \\
\hline 47 & Kruglogorsk-313 & 54.92 & 59.92 & 1975 & 2.79 & $39-580$ & 29 \\
\hline 48 & Md-721 & 61.45 & 59.95 & 1989 & & $30-380$ & 36 \\
\hline 49 & Jah-699 & 61.18 & 59.97 & 1986 & & $40-510$ & 48 \\
\hline 50 & Kuv-271 & 55.65 & 60.05 & 1978 & & $40-600$ & 29 \\
\hline 51 & Kuv-283 & 55.65 & 60.05 & 1978 & & $20-600$ & 30 \\
\hline 52 & KR-8802 & 58.37 & 60.07 & 1994 & & $30-600$ & 58 \\
\hline 53 & Dg-2003 & 56.72 & 60.08 & 1978 & & $20-410$ & 40 \\
\hline 54 & $\mathrm{Zu}-3312$ & 56.48 & 60.12 & 1980 & & $30-520$ & 50 \\
\hline 55 & Ilmenskaya-1 & 55.00 & 60.17 & 1993 & 1.72 & $10-590$ & 58 \\
\hline 56 & Kuvatal-165 & 55.67 & 60.17 & 1975 & 2.43 & $40-580$ & 29 \\
\hline 57 & Gu-3184 & 56.47 & 60.20 & 1980 & & $35-320$ & 30 \\
\hline 58 & Chu-2674 & 56.37 & 60.23 & 1995 & & $20-380$ & 37 \\
\hline 59 & Мa-8002 & 55.35 & 60.73 & 1994 & & $40-600$ & 56 \\
\hline 60 & Ma-8304 & 55.35 & 60.73 & 1994 & & $12-590$ & 59 \\
\hline 61 & Мa-8505 & 55.35 & 60.73 & 1994 & & $18-600$ & 58 \\
\hline 62 & 42 & 54.08 & 60.83 & 1977 & 2.50 & $40-280$ & 25 \\
\hline 63 & 62 & 54.20 & 60.83 & 1990 & 2.50 & $20-600$ & 59 \\
\hline 64 & Br-3190 & 56.87 & 60.83 & 1977 & & $30-480$ & 25 \\
\hline 65 & $\mathrm{Br}-3420$ & 56.87 & 60.83 & 1977 & & $20-480$ & 25 \\
\hline 66 & Techinskaya- 885 & 55.67 & 61.58 & 1976 & 2.75 & $20-570$ & 28 \\
\hline 67 & Djetygara-175 & 52.08 & 61.67 & 1982 & 3.44 & $29-356$ & 21 \\
\hline 68 & Djetygara-350 & 52.08 & 61.67 & 1982 & 3.23 & $50-502$ & 27 \\
\hline 69 & Kuzhai-S4 & 52.58 & 62.75 & 1977 & 2.16 & $40-600$ & 29 \\
\hline 70 & S8 & 52.58 & 62.75 & 1990 & 1.99 & $40-600$ & 29 \\
\hline 71 & Cholpon-1 & 42.65 & 77.08 & 1974 & 1.75 & $40-240$ & 11 \\
\hline 72 & Djerek-297 & 50.25 & 79.75 & 1978 & 2.50 & $50-380$ & 20 \\
\hline
\end{tabular}


Table 1. (continued)

\begin{tabular}{|c|c|c|c|c|c|c|c|}
\hline $\begin{array}{l}\text { Index } \\
\text { Number }\end{array}$ & $\begin{array}{c}\text { Borehole } \\
\text { Identification }\end{array}$ & $\begin{array}{c}\text { Latitude, } \\
{ }^{\circ} \mathrm{N}\end{array}$ & $\begin{array}{l}\text { Longitude, } \\
{ }^{\circ} \mathrm{E}\end{array}$ & $\begin{array}{l}\text { Log } \\
\text { Year }\end{array}$ & 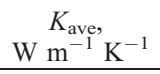 & $\begin{array}{c}\text { Depth } \\
\text { Range, m }\end{array}$ & $\begin{array}{c}\text { Number of } \\
\text { Measurements }\end{array}$ \\
\hline 73 & Gorn-705 & 51.00 & 81.47 & 1990 & 3.00 & $20-600$ & 34 \\
\hline 74 & Zmeinog-301 & 51.17 & 82.16 & 1974 & 2.50 & $20-320$ & 31 \\
\hline 75 & Irty-1216 & 50.17 & 82.33 & 1990 & 3.30 & $20-400$ & 24 \\
\hline 76 & Zaeltsovski-8 & 55.17 & 82.83 & 1991 & 2.40 & $50-210$ & 17 \\
\hline 77 & Kolyvan-15 & 55.40 & 82.87 & 1991 & 2.13 & $40-240$ & 21 \\
\hline 78 & Belor-98 & 51.00 & 82.92 & 1990 & 2.10 & $63-446$ & 97 \\
\hline 79 & Dolgaya & 49.50 & 83.67 & 1990 & 2.86 & $20-246$ & 114 \\
\hline 80 & Gonba-416 & 53.37 & 83.87 & 1990 & 2.50 & $50-210$ & 24 \\
\hline 81 & Bogatyrevo-2045 & 49.83 & 84.33 & 1977 & 3.40 & $50-570$ & 53 \\
\hline 82 & Bogatyrevo-3096 & 49.83 & 84.33 & 1977 & 3.40 & $23-500$ & 28 \\
\hline 83 & Agas-3 & 55.00 & 89.50 & 1990 & 2.33 & $70-220$ & 16 \\
\hline 84 & Irba-268 & 54.12 & 92.92 & 1990 & 2.43 & $60-600$ & 28 \\
\hline 85 & Hovu Aksi-582 & 51.17 & 93.47 & 1974 & 2.50 & $80-450$ & 38 \\
\hline 86 & Khab-23 & 54.00 & 93.75 & 1990 & 2.60 & $50-600$ & 36 \\
\hline 87 & Tabrat-20 & 53.83 & 93.83 & 1990 & 2.07 & $30-450$ & 24 \\
\hline 88 & Ak Sug-49 & 59.48 & 96.67 & 1978 & 3.50 & $90-450$ & 19 \\
\hline 89 & Yakutia-108 & 66.42 & 112.50 & 1987 & 3.00 & $60-400$ & 18 \\
\hline 90 & Yakutia-329 & 66.42 & 112.50 & 1986 & 3.00 & $60-400$ & 18 \\
\hline 91 & Yakutia-81 & 66.42 & 112.50 & 1991 & 3.00 & $80-300$ & 12 \\
\hline 92 & Ckb-14-t & 63.80 & 123.18 & 1988 & 2.00 & $50-480$ & 32 \\
\hline 93 & Ckb-9-m & 63.51 & 123.88 & 1987 & 2.00 & $50-420$ & 38 \\
\hline 94 & Ckb-68-m & 63.75 & 124.07 & 1987 & 2.00 & $30-560$ & 54 \\
\hline 95 & Ckb-66-m & 63.73 & 124.20 & 1987 & 2.00 & $20-350$ & 34 \\
\hline 96 & Kular-201 & 70.65 & 134.50 & 1981 & 2.50 & $30-220$ & 10 \\
\hline 97 & Kular-307 & 70.63 & 134.53 & 1981 & 2.50 & $20-210$ & 11 \\
\hline 98 & Tirekhtyakh-24 & 69.02 & 139.25 & 1988 & 2.00 & $20-200$ & 14 \\
\hline 99 & Tirekhtyakh-200 & 68.98 & 139.28 & 1988 & 2.00 & $30-200$ & 13 \\
\hline 100 & Cherpunia-28-a & 71.12 & 141.77 & 1987 & 3.00 & $20-300$ & 14 \\
\hline 101 & Cherpunia-23 & 71.12 & 141.82 & 1986 & 2.50 & $38-207$ & 10 \\
\hline
\end{tabular}

millennium will have no significant expression below that depth.

\section{Inversion}

[10] The reconstruction of a GSTH from a subsurface temperature profile involves taking a temperature versus depth profile at a given time (the year of logging), and inverting it to produce a temperature versus time profile at a given depth (in this case, the ground surface). This is in essence a process that estimates the time-dependent surface temperature boundary condition that generated the borehole temperature profile observed at the time of logging. The procedure can be generalized to simultaneously invert ensembles of borehole logs from several locations or several logs at a single location measured at different times. Many different inversion schemes have been utilized by various investigators [Shen and Beck, 1991; Wang, 1992; Mareschal and Beltrami, 1992; Bodri and Cermak, 1995; Cooper and Jones, 1998; Kennedy et al., 2000] to reconstruct this timedependent surface boundary condition.

[11] Here we reconstruct a GSTH from each borehole temperature profile using a Bayesian estimation technique [Shen and Beck, 1991]. A Bayesian inversion allows an a priori estimate of the GSTH to play a role in the inversion. If the a priori estimate is in conflict with the observations, the inversion will suggest adjustments that would make it conform better to the observations. In inverting each borehole profile, we adopt as the a priori GSTH estimate a null hypothesis, i.e., an assertion that the subsurface temperatures reflect only the steady state flow of heat from the deep interior and that the surface temperature at the borehole site has not changed over the past five centuries. This null hypothesis is a very conservative estimate of the climate history, and places a heavy burden on subsurface observations if it is to be rejected. Additionally, this null hypothesis is independent of and unbiased toward any particular preconception of the climate history.

\subsection{Diffusion, Signal, and Noise}

[12] Climatic fluctuations in the ground surface temperature (the "signal") propagate downward into the rock by thermal conduction, as attenuating thermal waves superimposed on the temperature signature of the deeper heat flux. The depth to which the signal can be observed is dependent on the amplitude, duration and spectral composition of the temperature changes that occur at the surface, and the presence and strength of nonclimatic perturbations to subsurface temperatures (the "noise").

[13] In conductive heat transfer, surface disturbances diminish exponentially with depth beneath the surface, but the decay is not spectrally uniform. Lower-frequency disturbances attenuate less with depth than do those of higher frequency. Thus the Earth acts as a low-pass frequency filter, allowing lower-frequency perturbations to propagate to greater depths than higher frequencies. Therefore, at increasing depths below the surface only progressively longer-term temperature trends are imprinted. Eventually, however, disturbances of all frequencies are attenuated to amplitudes below the level of the noise. Noise suppression techniques can help to identify the signal even when it is immersed in noise, but ultimately, at some depth the signal becomes too small to be recognized.

[14] Noise in the subsurface temperature field can arise in many ways. The underlying theory tying the surface boundary condition to the subsurface temperature field is the one-dimensional theory of heat conduction. Any departures in the natural setting from simple one-dimensional (vertical) 
heat conduction will introduce noise into the temperature field and obscure the evolving climate signal. Departures that impart two and three dimensionality to the subsurface temperatures include surface topography, vegetation patterns, and hydrological features and some types of subsurface heterogeneity (horizontal layers with different physical properties, however, can be accommodated). Any significant heat transfer by nonconductive processes, such as advection by groundwater, will also add noise to the system.

\subsection{Parameterization}

[15] In formulating an inverse problem, the investigators must decide what information they seek from the inversion. In the context of reconstructing a GSTH, one decision to be made addresses the level of temporal detail to be recovered. Because annual temperature fluctuations disappear into the noise below a few tens of meters depth, and the shallowest borehole temperature measurement commonly employed in climate reconstructions is at $20 \mathrm{~m}$ or deeper, clearly one cannot interrogate deep borehole profiles for annual variability. Because conductive heat transfer reveals progressively longer-period variability at greater depths, here we choose to focus on that long-term variability, and parameterize the GSTH in terms of century-long trends, i.e., the temperature change that has taken place in a given calendar century [Huang et al., 1996].

[16] This parameterization will not represent individual multidecadal climatic excursions such as those that repeatedly characterized various regions in the Northern Hemisphere during the Little Ice Age (LIA) in the time interval 1400-1900 [Grove, 1988]. The parameterization will, however, recognize the generalized effects of such excursions as a relatively cold century. Moreover, the effects of the LIA were not simultaneous everywhere; the cooler multidecadal excursions occurred at different times at different places. Because we also attempt to capture generalized geographic aspects of climatic history with spatial ensembles (regional, continental) of individual GSTH reconstructions achieved with the century-long parameterization, spatial patterns will also be smoothed and generalized.

[17] The century-long parameterization has been used in analyzing the global database of borehole temperature profiles to create global and hemispheric reconstructions [Huang et al., 2000]; here we use it in part to enable comparisons of widely separated regions within Russia, as well as with other continental and larger-scale climate reconstructions. This parameterization has the added advantage of being easily compared to century-long trends in the instrumental record of surface air temperature [Jones et al., 1999a].

[18] We seek from the inversion the five century-long trends of ground surface temperature that produce the transient component of the subsurface temperature profile. These five-century-long trends together represent the GSTH since the year 1500. Although some boreholes may yield resolvable trends for times prior to 1500 , we do not attempt to extend the analysis to earlier times.

\subsection{Thermophysical Properties}

[19] In a conductive medium it is the thermal diffusivity that governs the space-time evolution of the temperature field. Accordingly the thermal diffusivity is central to the interpretation of the transient component of the subsurface temperature profile, and hence to the reconstruction of the GSTH. The diffusivity provides the link between current temperature perturbations over various depth ranges in the borehole and the timing of past temperature excursions at the surface that gave rise to the present-day subsurface expression. Although the thermal diffusivity of rock is dependent on the thermal conductivity (it is defined as the ratio of the conductivity to the product of the density and specific heat), the diffusivity shows much less variability than the conductivity alone, because the other factors in the ratio commonly vary sympathetically with the conductivity. Although the conductivity may vary by a factor of 2 in different rocks (see section 3.4), the value of $1.0 \pm 0.2 \times$ $10^{-6} \mathrm{~m}^{2} \mathrm{~s}^{-1}$ is a good estimate for the thermal diffusivity in a wide variety of rocks. Here we use $1.0 \times 10^{-6} \mathrm{~m}^{2} \mathrm{~s}^{-1}$ as a standard value in all of the inversions.

[20] The possible errors associated with using a standard value of thermal diffusivity lie in constraining the time period over which the inferred temperature changes occur. A smaller diffusivity distributes changes over a longer period of time, whereas a larger diffusivity distributes changes over a shorter time. We invert each borehole temperature $\log$ to yield a 500-year ground surface temperature history, using the uniform value of $1.0 \times 10^{-6} \mathrm{~m}^{2} \mathrm{~s}^{-1}$. The $\pm 20 \%$ range of diffusivity would yield a reconstructed history of the same magnitude but in a temporal frame of 415-600 years.

[21] For an individual borehole the actual rock diffusivity may deviate from the assumed standard value. A mean reconstruction, however, is aggregated from an ensemble of individual borehole reconstructions. Only if there were a systematic bias of the diffusivity away from the standard value throughout the ensemble would a timescale error be introduced. In section 3.5 we discuss regional stacking of individual borehole reconstructions as a signal enhancement procedure. One source of noise that is suppressed in such stacking is the variability of thermal diffusivity from borehole to borehole.

\subsection{Separation of Steady State From Transient}

[22] The steady state subsurface temperature field is determined by the outward flux of heat from the deeper interior and the thermal conductivity structure of the medium. The thermal conductivity of common upper crustal rocks typically ranges between 2 and $4 \mathrm{~W} \mathrm{~m}^{-1} \mathrm{~K}^{-1}$. In a homogeneous medium with uniform conductivity, the steady state is expressed as a linear increase of temperature with depth. With a sufficiently deep borehole temperature profile, one can easily identify the linear segment visually, in a depth range beyond which the downward propagating transient has been attenuated to an amplitude that no longer can be seen above the noise level.

[23] Where the subsurface is horizontally layered, the steady state temperature profile is a piecewise-linear increase of temperature with depth, in which the gradient through the individual layers is inversely proportional to the conductivity of each layer. A borehole that displays such a piecewise-linear temperature profile can be successfully inverted only if the thermal conductivity of each layer is known; otherwise the successive changes in slope of the profile might be misinterpreted as resulting from oscillations in the surface temperature. In the inversion schemes in 


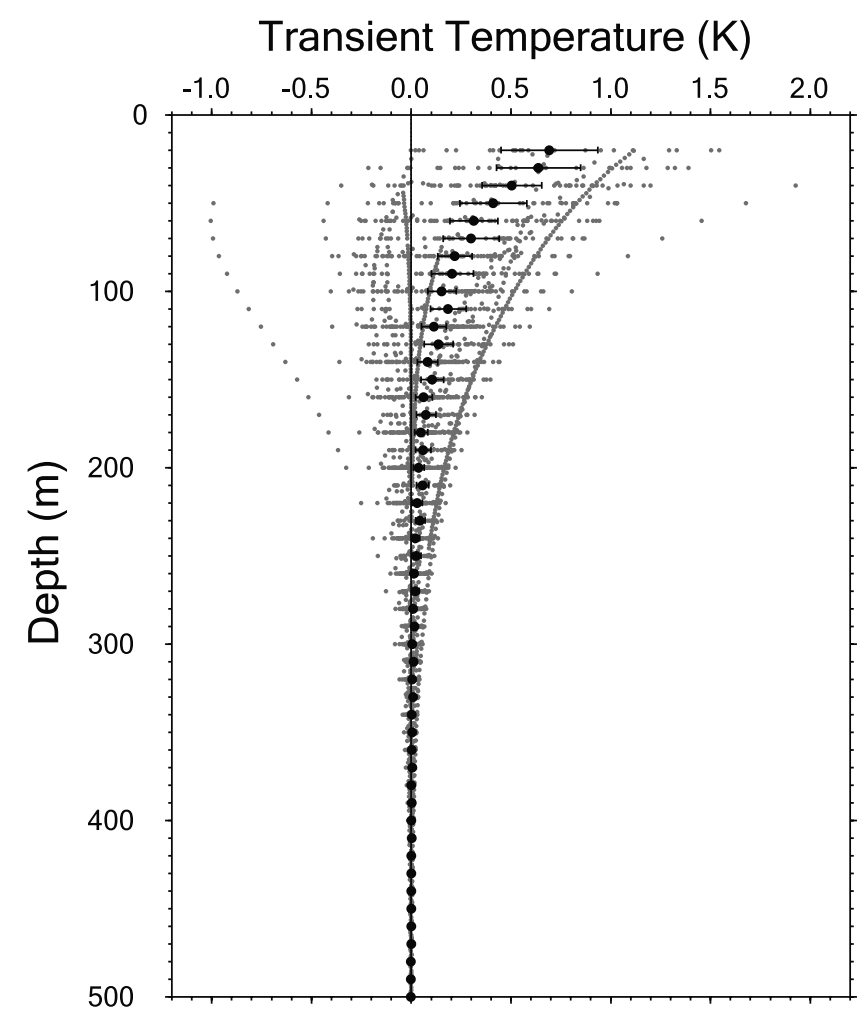

Figure 2. Ensemble of the transient component of subsurface temperature versus depth from each of the boreholes in the Russian data set. The mean and standard error of the mean in each $10 \mathrm{~m}$ depth interval is shown in bold.

common use for estimating the GSTH the estimation of the steady state component of the temperature field is achieved simultaneously with the estimation of the transient.

[24] In Figure 2 we display as an ensemble the transient component of all the borehole temperature profiles described in Table 1. Also shown is the average transient for the complete ensemble at $10-\mathrm{m}$ depth intervals. This mean transient is positive at every depth to at least $300 \mathrm{~m}$, indicating a history of warming extending back several centuries.

[25] About 15-20\% of the individual residual profiles display a negative transient, with maximum amplitude at depths $<100 \mathrm{~m}$. In these holes, cooler conditions persisted until later times than in the other boreholes. The warming that has led to the curvature of these profiles toward higher temperatures in the upper hundred meters has occurred more recently than in the other holes where the positive transient extends to greater depths.

[26] In Figure 2 one can also see two notable largeamplitude transients, one positive (Mg-3) and one negative (Ckb-14-t). These are relative outliers from the general distribution of transients, but because the temperature logs for these two boreholes met all quality control criteria for inclusion in the analysis, they have not been excluded from the ensemble.

\subsection{Noise Suppression Through Regional Stacking}

[27] Following inversion of each borehole separately, we construct regional reconstructions by averaging the centurylong trends of temperature change indicated in each bore- hole within the designated region. This procedure, first explored by Beltrami et al. [1992] and examined in detail by Pollack et al. [1996], is analogous to the stacking of seismograms in seismic data analysis, and can lead to substantial enhancement of a signal that may be present but not apparent in the individual borehole reconstructions. It represents a second stage of signal enhancement and noise suppression, one that takes place outside of the inversion procedure. The inversion process itself comprises the first stage of noise suppression, in the form of smoothing parameters imposed on both the temperature data and the GSTH, as well as through the parameterization of the GSTH. Simultaneous inversion of the observations from several boreholes is another ensemble analysis technique that suppresses noise and identifies a signal common to all of the boreholes in the simultaneous inversion [Beltrami et al., 1992; Pollack et al., 1996; Beltrami et al., 1997]; this approach has earlier been employed by Golovanova et al. [2001] in the analysis of the boreholes from the southern Urals. These signal enhancement procedures, simultaneous inversion or postinversion stacking, do not, however, lead to an improved temporal resolution of the signal. They simply enhance signal recognition. The temporal resolution is defined by the diffusion process, the characteristics of the data, and the inversion parameters.

\section{Climatic Reconstructions}

[28] Within the data array defined by the borehole locations shown in Table 1 and Figure 1 we identify three geographic groups: a Urals group comprising 66 boreholes (index numbers 5-70), a southwest Siberia group comprising 18 boreholes (index numbers 71-88), a northeast Siberia group with 13 boreholes (index numbers 89-101), and an "all-Russia" ensemble comprising all 101 sites listed in Table 1, i.e., the full data set. For each of these ensembles we have derived an average five-century ground surface temperature history, and an uncertainty band defined by \pm 1 standard error of the mean.

\subsection{Urals}

[29] The largest and densest subset of data is situated along the north-south trending Ural Mountains, in the latitude range of $45^{\circ}-65^{\circ} \mathrm{N}$, along the boundary between European and Asian Russia. About two thirds of the full Russian data set derive from the Urals, and therefore it is probably the most robust ensemble within the full Russian data set. Independent climate-related investigations have been carried out in both the central Urals [Khachai et al., 1996; Demezhko, 2001] and the southern Urals [Stulc et al., 1997, 1998; Golovanova et al., 2001], with some overlap. These studies show that in general, warming began in each region early in the 19th century, and accelerated in the 20th century, with the total warming in each region in the range of $1.0-1.5 \mathrm{~K}$. Episodes of the Little Ice Age have been identified in several of these boreholes.

[30] We have inverted all of the boreholes in this Ural ensemble individually, with the centennial parameterization described above. This inversion is a much more sparsely parameterized variant of the functional space inversion (FSI [Shen and Beck, 1991]) employed in some of the earlier Uralian studies. Because our inversion seeks only the 


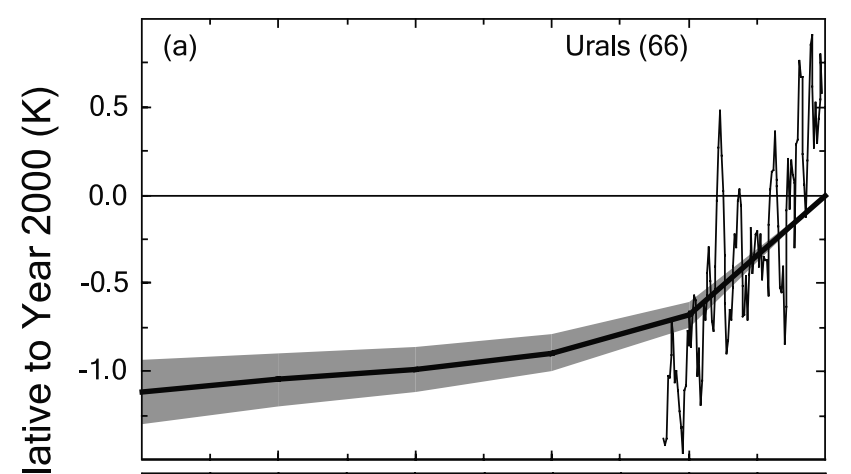

(b)

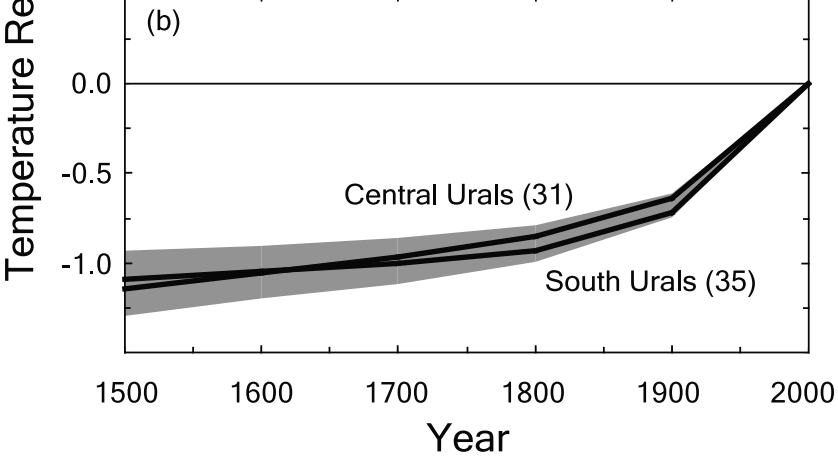

Figure 3. (a) Average ground surface temperature history (GSTH) for the full Urals borehole ensemble comprising 66 sites. Shaded area represents \pm 1 standard error of the mean. Superimposed is the time series (5-year moving average) of the surface air temperature (SAT) [Jones et al., 1999a]. Because the SAT is referenced to the mean over 19611990, and the geothermal reconstruction is referenced to the year 2000, we have shifted the SAT series along the temperature axis to enable an easier comparison of their respective trends. (b) Average GSTHs for the Central Urals subset (31 sites) and the South Urals subset (35 sites), shown within the standard error envelope of the full Urals data set shown above in Figure 3a.

century-long trends in the ground surface temperature, it yields a smoother, more temporally distributed, and more conservative GSTH than more heavily parameterized representations. The five-century average reconstruction for the full Urals ensemble is shown in Figure $3 \mathrm{a}$ and summarized in Table 2. The total warming experienced by the ground is $1.12 \pm 0.18 \mathrm{~K}$, within the $1.0-1.5 \mathrm{~K}$ range found in the earlier studies. Of this total five-century warming, $80 \%$ occurred in the 19th and 20th centuries, with more than
$60 \%(0.68 \mathrm{~K})$ occurring in the 20th century alone. The magnitude of the total warming and its strong signature in the 19th and 20th centuries are consistent with the earlier estimates, derived using different parameterizations and noise suppression techniques. The colder (although gradually warming) history in the 16 th, 17 th, and 18 th centuries is likely a smooth representation of the LIA in the region.

[31] We have also searched for regional variability within the Urals region by dividing the data set at $55^{\circ} \mathrm{N}$. This results in subensembles of 31 sites (central Urals) and 35 sites (south Urals), respectively. The average reconstructions for these subensembles are shown in Figure $3 b$, superimposed on the uncertainty envelope of the full Urals reconstruction. Both the central and southern histories are contained within the uncertainty envelope of the full ensemble history, suggesting that there is no significant difference between the two.

[32] The earlier investigators of various parts of this Urals data set all recognized the need for averaging or simultaneous inversion of individual boreholes to reveal a regional climate signal amidst site-specific nonclimatic signatures. Stulc et al. [1998] found that ensembles of 10-15 boreholes consistently gave similar composite results. Golovanova et al. [2001] elected simultaneous inversion, and identified several boreholes that resisted convergence to a common history when inverted simultaneously with other boreholes. We have also constructed an average history for the southern Urals (and the entire Urals) exclusive of those boreholes identified as problematic. The differences in centennial rates of change between ensembles inclusive and exclusive of the problematic boreholes never exceeded $0.02 \mathrm{~K}$ per century. We conclude that whatever characteristics those boreholes displayed that led to cautionary tagging in the earlier analyses were inconsequential to the centennially parameterized reconstructions and therefore have been retained in our analysis.

\subsection{Southwest Siberia}

[33] This ensemble, comprising 18 boreholes from southwestern Siberia, represents a varied terrain that includes the Altai Mountains and foothills and regions of lesser relief between the $\mathrm{Ob}$ and Yenisei Rivers, roughly between Novosibirsk and Krasnoyarsk. In this region, as in the Urals, the previous investigations (using the FSI inversion scheme of Shen and Beck [1991]) also identified warming in individual boreholes in the range of $1.0-1.5 \mathrm{~K}$ that began in the early to mid-19th century and continued throughout the 20th century [Sukhorukova and Duchkov, 1998; Duchkov et al., 2000, 2002; Duchkov and Pollack, 2002]. However,

Table 2. Century-Long Rates of Change in GST and Total Five-Century Change in GST in the Urals, Southwest Siberia, Northeast Siberia, and All-Russia ${ }^{\mathrm{a}}$

\begin{tabular}{|c|c|c|c|c|c|c|c|}
\hline \multirow[b]{2}{*}{ Region } & \multicolumn{5}{|c|}{ Century-Long Rates of GST Change, K/100 years } & \multirow{2}{*}{$\begin{array}{l}\text { Five-Century } \\
\text { GST Sum, K }\end{array}$} & \multirow{2}{*}{$\begin{array}{l}\text { 20th Century } \\
\text { SAT, K/100 years }\end{array}$} \\
\hline & 16th & 17 th & 18 th & 19th & 20 th & & \\
\hline Urals $\left(45^{\circ}-65^{\circ} \mathrm{N}, 55^{\circ}-65^{\circ} \mathrm{E}\right)$ & 0.067 & 0.061 & 0.092 & 0.216 & 0.679 & 1.120 & 1.32 \\
\hline SW Siberia $\left(45^{\circ}-60^{\circ} \mathrm{N}, 75^{\circ}-100^{\circ} \mathrm{E}\right)$ & 0.077 & 0.081 & 0.099 & 0.165 & 0.526 & 0.948 & 1.54 \\
\hline NE Siberia $\left(60^{\circ}-75^{\circ} \mathrm{N}, 110^{\circ}-150^{\circ} \mathrm{E}\right)$ & -0.061 & -0.076 & -0.063 & 0.063 & 0.672 & 0.535 & 0.88 \\
\hline All-Russia $\left(45^{\circ}-75^{\circ} \mathrm{N}, 55^{\circ}-150^{\circ} \mathrm{E}\right)$ & 0.054 & 0.045 & 0.065 & 0.174 & 0.645 & 0.983 & 1.33 \\
\hline North America $\left(30^{\circ}-65^{\circ} \mathrm{N}, 65^{\circ}-125^{\circ} \mathrm{W}\right)$ & -0.041 & 0.038 & 0.151 & 0.285 & 0.660 & 1.093 & 0.69 \\
\hline
\end{tabular}

${ }^{a}$ As shown in Figures 3, 4, 5, and 6. For comparative purposes, these quantities are also shown for North America. Also tabulated are the SAT temperature trends for the 20th century, calculated from Jones et al.'s [1999a] data for the full century 1900-2000. 


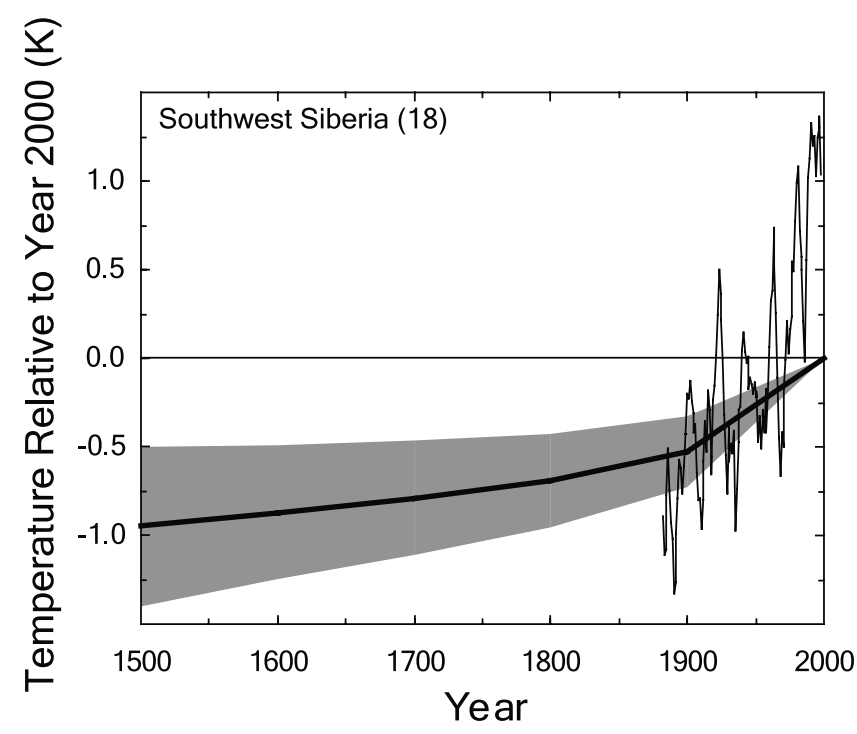

Figure 4. Average ground surface temperature history (GSTH) for the southwest Siberia borehole ensemble comprising 18 sites. Shaded area represents \pm 1 standard error of the mean. Superimposed is the time series (5-year moving average) of the surface air temperature (SAT) [Jones et al., 1999a]. Because the SAT is referenced to the mean over 1961-1990, and the geothermal reconstruction is referenced to the year 2000, we have shifted the SAT series along the temperature axis to enable an easier comparison of their respective trends.

there has been no previous analysis of this complete ensemble prior to the analysis we present here.

[34] Our average reconstruction for this ensemble, shown in Figure 4 and summarized in Table 2, indicates a total warming over five centuries of about $0.95 \pm 0.45 \mathrm{~K}$, with more than $75 \%(0.70 \mathrm{~K})$ occurring in the most recent two centuries. This warming is slightly less in magnitude, and more temporally distributed than the results presented by Sukhorukova and Duchkov [1998]. The differences arise in part because the borehole ensemble used by Sukhorukova and Duchkov was somewhat different from the one used here, but more probably from the different parameterizations. As discussed earlier, the parameterization for centurylong trends inevitably leads to a smaller amplitude, smoother, and more temporally distributed reconstruction.

\subsection{Northeast Siberia}

[35] This ensemble comprises only 13 boreholes spread widely over northeastern Siberia, generally in the vicinity of the Lena River. Three boreholes are located near Yakutsk [Klimovsky and Gotovtsev, 1994], six east of Tiksi (A. Vasiliev, personal communication, 2000), and four west of Yakutsk (S. Berkovchenko, personal communication, 2000) along the Viluyi River, a tributary to the Lena. All are boreholes drilled into permafrost, all have mean annual surface temperatures below $0^{\circ} \mathrm{C}$, and all display temperature-depth profiles that remain below zero throughout the entire depth range. Because the entire vertical section (below a thin seasonally active surficial zone) is frozen, the medium is effectively a conducting medium, free of advection, and amenable to climate reconstructions in the same fashion as boreholes drilled in rock. Inasmuch as ice has a thermal diffusivity very similar to typical crustal rock, no special adaptation of thermophysical values are required to undertake the standardized inversion of these profiles. Summer temperatures do rise above $0^{\circ} \mathrm{C}$, leading to a thin surficial active zone, but in an annual cycle latent heat effects appear to be conservative, influencing the effective mean annual ground surface temperature only in second-order ways [Osterkamp and Romanovsky, 1996; Zhang, 1993].

[36] Our average reconstruction for this small ensemble, shown in Figure 5 and summarized in Table 2, shows about $0.67 \pm 0.21 \mathrm{~K}$ of warming in the 20 th century, with the earlier centuries suggesting little change on average, but within a fairly large uncertainty range that allows either modest warming or cooling. This uncertainty arises from at least two reasons: the relatively small size of the ensemble, and the large region over which results are averaged. The 20 th century warming is very similar to that observed in the large Urals ensemble, and slightly greater than that observed in the southwest Siberian ensemble. The 16th through 19th centuries in this region appear to be warmer than reconstructed in southwest Siberia and in the Urals, a result that appears also in dendroclimatological reconstructions from northern Siberia [Briffa et al., 2001]. This characteristic is discussed further in section 5.1.

\subsection{All-Russia}

[37] We now present the full data set as a single ensemble of 101 boreholes, and reconstruct a generalized GSTH for the entire Russian territory represented by these data. This reconstruction, shown in Figure 6 and summarized in Table 2, is characterized by a five-century warming of $0.98 \pm 0.15 \mathrm{~K}$, of which more than $80 \%(0.82 \mathrm{~K})$ occurred in the 19th and

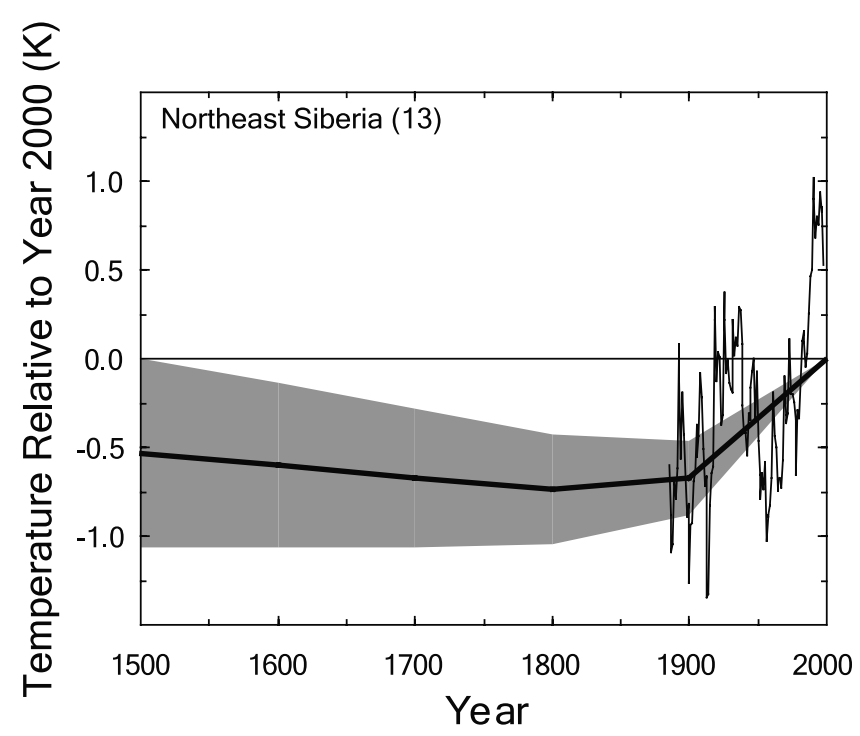

Figure 5. Average ground surface temperature history (GSTH) for the northeast Siberia borehole ensemble comprising 13 sites. Shaded area represents \pm 1 standard error of the mean. Superimposed is the time series (5-year moving average) of the surface air temperature (SAT) [Jones et al., 1999a]. Because the SAT is referenced to the mean over 1961-1990, and the geothermal reconstruction is referenced to the year 2000, we have shifted the SAT series along the temperature axis to enable an easier comparison of their respective trends. 


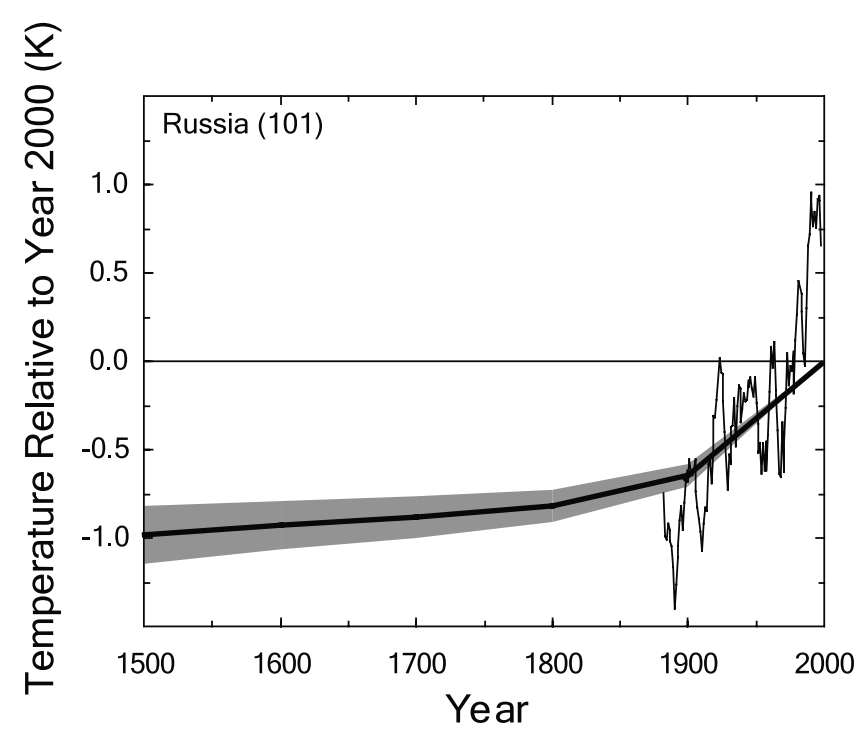

Figure 6. Average ground surface temperature history (GSTH) for the full Russian borehole ensemble comprising 101 sites. Shaded area represents \pm 1 standard error of the mean. Superimposed is the time series (5-year moving average) of the surface air temperature (SAT) [Jones et al., 1999a]. Because the SAT is referenced to the mean over 1961-1990, and the geothermal reconstruction is referenced to the year 2000, we have shifted the SAT series along the temperature axis to enable an easier comparison of their respective trends.

20 th centuries. The warming of the 20 th century, $0.65 \mathrm{~K}$, is greater than in any of the four previous centuries, indeed greater than the cumulative warming of the previous four centuries. It is a robust feature that can be seen in each of the regional subsets comprising the all-Russia ensemble. The generally cool 16th, 17th, and 18th centuries reflect the presence of the LIA in the Urals and southwest Siberia ensembles, and which together overshadow northeast Siberia in the all-Russia reconstruction.

[38] The North American continent is another large area that provides a broad sweep of unobstructed flatlands from the Arctic southward to $30^{\circ} \mathrm{N}$ latitude. In North America the continent wide ensemble of boreholes includes 381 sites [Huang and Pollack, 1998], a data set almost four times larger than the 101 borehole ensemble for Russia. The warming in North America since 1500 has been $1.09 \mathrm{~K}$, similar to the $0.98 \mathrm{~K}$ seen in the smaller Russian data set. For the 20th century alone, North America and Russia show warming of $0.66 \pm 0.05 \mathrm{~K}$ and $0.65 \pm 0.07 \mathrm{~K}$, respectively. These warming trends over two large continental areas in the Northern Hemisphere, as inferred from the geothermal archive in the respective regions, are remarkably similar.

\section{Comparison With SATs}

[39] Borehole logs provide direct measurements of temperature versus depth, from which we derive estimates of the GSTH. It is useful to compare trends in the GSTH estimated from subsurface temperatures, with trends in the surface air temperature (SAT) derived from meteorological stations. The SAT data have been assembled and analyzed by several research groups worldwide; here we make use of the well-known compilation of the Climate Research Unit of the University of East Anglia in the United Kingdom [Jones et al., 1999a, 1999b].

[40] Shown in Figures 3, 4, 5, and 6, superimposed on the borehole reconstructions, are the instrumental SAT records (5-year moving average) for each region, taken from the Jones et al. [1999a] [see also Jones et al., 1999b] updated tabulation. In each region there is a sharp increase in SAT during the last few decades of the 20th century, a warming that has affected Arctic sea ice, snow cover, precipitation and many other characteristics (see the summary by Serreze et al. [2000]). This dramatic increase in recent decades affects the century-long trend of the SAT (Table 2), yielding an average SAT rate that, not surprisingly, is in excess of the geothermal estimate of the 20th century warming.

[41] The reasons for the lower geothermal estimates of 20th century warming are several: the geothermal reconstructions do not capture the rapid increase in the SAT in the last few decades because (1) more than half of the boreholes were logged prior to 1983, and therefore can offer no perspectives on later changes, (2) decadal temperature fluctuations are strongly attenuated in the first $50 \mathrm{~m}$ below the surface, and temperature logs that begin at greater depths will have difficulty in detecting and reconstructing decadal excursions, and ( 3 ) the parameterization for the linear trend over the entire century must accommodate all interdecadal fluctuations, large or small, positive or negative, throughout the century, in a single estimated trend. Additionally, the geothermal estimates are conservative because (4) the noise suppression parameters of the inversion inevitably suppress some signal, leading to a somewhat muted GSTH; and (5) the conservative a priori null hypothesis of the inversion, as an initial hypothesis on the GSTH, begins the inversion with a totally muted history, and places a nontrivial burden on the borehole temperatures to force a rejection of the null hypothesis. It is clear that the geothermal estimates of 20th century (and earlier) warming are likely to be lower bounds on the actual warming. The composite SAT for these regions may also suffer from a relatively sparse distribution of reporting meteorological stations.

\section{Climate Proxies}

[42] In addition to the instrumental SAT record, there is also indirect evidence derived from a variety of other sources, collectively known as climate proxies. As the word proxy implies, these indirect observations are complementary to the instrumental record in time intervals where both exist; for times prior to the beginning of the instrumental record, they can serve as imperfect estimates of temperature variability. Traditional proxies for aspects of the SAT on continents include historical records of freeze and thaw dates of major lakes and rivers; the composition, thickness, and latewood density of tree rings; sequences of lacustrine varves; pollen composition and distribution; loess properties, and isotopic variations in ice cores. Subsurface temperatures are sometimes referred to as proxies for the SAT as well, because they need to be inverted to recover an estimate of the GST, which in turn may be imperfectly correlated with the SAT. However, subsurface temperature measurements are different from many proxies in that, 
unlike conventional proxies, they require no empirical calibration to be transformed into temperature. They are direct observations of temperature with sensitive wellcalibrated thermometers.

\subsection{Dendroclimatology}

[43] Dendroclimatology (the analysis of tree rings for historical climatologic data) has been an important contributor to assessments of climate change in Russia, principally through the efforts of two major research groups: one in the Institute of Plant and Animal Ecology in Ekaterinburg, led by S. G. Shiyatov and the other in the Institute of Forest in Krasnoyarsk led by E. A. Vaganov. These two research groups, singly, together, and sometimes in collaboration with dendroclimatologists from Europe and North America, have amassed a large body of information relevant to the recent climate history of Russia as revealed by tree growth characteristics [Shiyatov, 1986; Vaganov et al., 1996; Vaganov and Shiyatov, 1998].

[44] Vaganov and Shiyatov [1998] present a composite representation of growth characteristics in the Siberian forests, from the Urals to the far east, calibrated against a regional average SAT for the period 1880-1980. Their scaled composite dendrochronology is consistent with the allRussia geothermal estimate of the temperature trend over the 20th century shown in Figure 6 and Table 2, within the indicated uncertainty of the geothermal estimate. The significance of this consistency is that the 20th century warming is manifest comparably in the SAT, the dendrochronology and the subsurface temperatures.

[45] Because tree rings offer a clear annual chronology, they have been particularly useful in defining interannual climatic variability. However, trees also exhibit a long-term thinning of the annual rings and a long-term decline in latewood density, both related simply to the growth and aging of the tree. This aging trend must be removed in order to focus on interannual variability associated with climate change. In filtering out the long-term growth trend via a process known as "detrending" or "standardization," it is uncertain how much variability related to long-term climatic changes survives. Recently, however, the process of standardization has been reexamined and refined, with particular attention to the problem of retaining the long-term variability related to climate, while removing the long-term aging trend [Briffa et al., 2001; Esper et al., 2002]. Each of these investigations incorporates novel but different approaches to identifying and removing the growth-related long-term variability, while retaining long-term variability not related to aging.

[46] Briffa et al. [2001] provide new estimates of temperatures in several regions in the Northern Hemisphere over roughly the past millennium. When compared to previous estimates obtained with different processing techniques, their new regional estimates are generally cooler in almost all precalibration periods. Of the cooler earlier centuries, the coolest conditions are found in the 17 th century. Their composite reconstruction of the full Northern Hemisphere indicates that the 20th century was the warmest in the last 600 years. Esper et al. [2002] also found, similar to Briffa et al. [2001], that reprocessing to retain the long-term climate information led to a Northern Hemisphere reconstruction that was generally cooler than earlier estimates, for at least the last eight centuries.

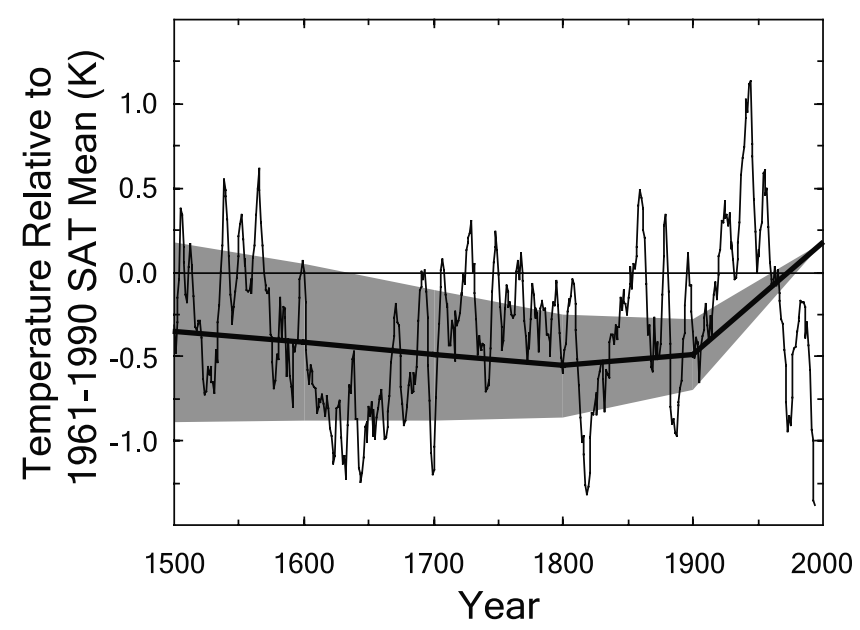

Figure 7. Average ground surface temperature history (GSTH) for the northeast Siberia borehole ensemble, as in Figure 6 except displayed relative to its 1961-1990 mean. Superimposed is the time series (5-year moving average) derived from the average of the three northern Siberia dendrochronologies (P, M, T in Figure 1) of Esper et al. [2002], scaled to the SAT (Jones et al. [1999a], referenced to the mean SAT over $1961-1990)$ over the region $65^{\circ}-$ $75^{\circ} \mathrm{N}, 60^{\circ}-110^{\circ} \mathrm{E}$.

[47] One exception to the generally cooler early centuries can be seen in the new reconstruction for northern Siberia, where 15 th century summers, according to the Briffa et al. [2001] treatment, are now estimated to have been as warm or warmer than those observed in the 20th century. We examine this exception in the context of the geothermal reconstruction for northeastern Siberia shown in Figure 5. This geothermal reconstruction also shows 16 th -18 th centuries that are more similar to the present-day than elsewhere in Russia, suggesting that perhaps there is a high-latitude region in Asia that has experienced a somewhat more moderate and less changing climate history.

[48] Here we compare the consistency of the dendroclimatological and geothermal reconstructions for this highlatitude region. Esper et al. [2002] show in their Northern Hemisphere data array three long chronologies from northern Russia (Polar Urals, Mangazeja, Taimyr) that can be scaled (calibrated) for comparison with the borehole results. These data sets have been studied by various investigators employing different data processing methodologies. We have selected the Esper et al. versions of these chronologies because of the special attention given in their data processing to retention of non-growth-related long-term information. We average the three chronologies to obtain a single characteristic regional chronology, and scale it with the grid-averaged annual SAT record [Jones et al., 1999a] for the region $65^{\circ}-75^{\circ} \mathrm{N}, 60^{\circ}-110^{\circ} \mathrm{E}$. In the scaling, we use the SAT record only from the interval $1881-1960$, in recognition of the observed divergence between tree ring indices and temperature in the last several decades of the 20th century [Briffa et al., 1998]. The scaled dendrochronological index and the northeastern Siberia geothermal reconstruction are shown together in Figure 7. Clearly, there is no contradiction in long-term trends between these two fully independent representations. Both indicate that the four 
centuries preceding the 20th century were more similar to the 20 th century in this region than elsewhere in Russia. The 20th century increase of temperature in this region, however, was similar to that experienced in Russian dendrochronologies and borehole ensembles from other regions [Vaganov and Shiyatov, 1998; Duchkov and Pollack, 2002].

\subsection{Soil Temperatures}

[49] Since the latter decades of the 19th century, meteorological stations have provided an instrumental record of the SAT, precipitation and other significant climatologic indicators for the territory of Russia. In addition to the instrumental record of the SAT, many Russian meteorological stations also have subsurface thermometers that record soil temperatures at several depths within the upper $3 \mathrm{~m}$ of soil. These observations began at many stations in the late 19th century, and can be found in printed government archives. Recently progress has been made in transforming these printed records into digital form, but the transformation has yet to be completed (see Zhang et al. [2001] for a discussion of the Russian archival data). However, one such archive, containing long-term records of soil temperature, SAT, precipitation, snowfall and snow thickness at the Irkutsk Observatory $\left(52^{\circ} \mathrm{N}, 104^{\circ} \mathrm{E}\right)$, has been investigated in detail [Zhang et al., 2001]. Both soil and air temperature data are available from 1898 to 1995 , essentially the whole of the 20th century.

[50] At Irkutsk, the SAT trend over the observation interval has two well-defined segments: an increase of $0.73 \mathrm{~K}$ per century from 1882 to 1965 , and a much more dramatic increase over the recent decades from 1966 onward. As mentioned earlier, borehole observations will not have captured this rapid increase in the SAT because it is so recent. Soil temperatures at Irkutsk also increased over the interval of observation at every depth, but with rates that diminish with depth: $2.23 \mathrm{~K}$ per century at $0.40 \mathrm{~m}$ depth but $1.22 \mathrm{~K}$ per century at $2.40 \mathrm{~m}$ depth. The rate of warming at each depth exceeds both the pre-1965 SAT warming rate at Irkutsk, and the 20th century ground surface warming rate of $0.52 \mathrm{~K}$ per century inferred from the southwest Siberia deep borehole temperature profiles some $1500 \mathrm{~km}$ to the west. While Irkutsk represents only one location, its data are both illustrative and instructive, and consistent with trends observed elsewhere in Russia [Pavlov, 1994, 1996].

[51] The Irkutsk Observatory data, and natural features in the area, offer several other indirect indicators of 20th century and longer-term warming. The soil freezing index (the cumulative degree days that the soil temperature at 0.4 $\mathrm{m}$ was below freezing) at Irkutsk has diminished by $20 \%$ over the interval of observation, and the duration of annual snow cover has diminished by $12 \%$. Similar observations of the date of freezing of the Angara River over more than two centuries have shown that the date of freezing has come 78 days later per century, and more than a century of data from nearby Lake Baikal shows a delay in annual freezing of 11 days per century and the annual ice breakup occurring earlier by 5 days per century [Magnuson et al., 2000].

\section{Conclusions}

[52] It is well recognized that the last few decades have seen dramatic warming in the high latitudes of the Northern Hemisphere [Serreze et al., 2000; Pavlov, 1996; Osterkamp and Romanovsky, 1996]. The geothermal archive of northern Alaska [Lachenbruch and Marshall, 1986] indicates that the warming characterizes much of the 20th century. Much longer records, such as the ice cores, lacustrine and marine sediments, and dendrochronologies examined by Overpeck et al. [1997], indicate that the warming began at least by the beginning of the 19th century, and accelerated in the 20th century.

[53] In Russia the warming has not been confined to the Arctic. The SAT record since 1880 [Jones et al., 1999a], the diminishing duration of annual lake and river ice [Magnuson et al., 2000], increasing soil temperatures in southern Siberia [Zhang et al., 2001] and the dendroclimatological studies of the Russian boreal and high-elevation forests [Vaganov and Shiyatov, 1998] together show that climate change has affected virtually all of Russia on a centennial timescale.

[54] Here we have examined yet another independent archive, the geothermal signature of climate change in much of Russia, as expressed in the Ural Mountain region, southwest Siberia and northeast Siberia, to reconstruct the general trends of changing surface temperature over the past five centuries. Our results also indicate that substantial warming has occurred across Russia in the 20th century, and that the warming is a continuation of warming that occurred in the 19th century and earlier. Of the total average increase in ground surface temperature of $\sim 1 \mathrm{~K}$ across Russia, more than half occurred in the 20th century alone, and $70-80 \%$ in the 19 th and 20th centuries taken together. The 16th through 18th centuries in the Urals and in southwest Siberia were on average about $0.1-0.2 \mathrm{~K}$ cooler than at the beginning of the 19th century, but northeast Siberia was more moderate in the 16th through 19th centuries, relative to the present-day, than the Urals or southwest Siberia. These geothermal results are consistent with a wide variety of instrumental, proxy and indirect evidence.

[55] Acknowledgments. We thank S. A. Alexeev, S. Berkovchenko, R. Dorofeeva, A. V. Pavlov, and A. Vasiliev for calling attention to borehole temperature data; E. R. Cook for providing the newly standardized Polar Ural, Mangazeja, and Taimyr dendrochronologies; and I. Andronikova for translations and summaries of Russian language papers. Financial support for this research came from NSF grant ATM-9902171, Russian Foundation for Basic Research grants 01-05-64776 and 02-05-96434, Integration Project 74 of the Siberian Branch, Russian Academy of Sciences, the International Geological Correlation Project 428, and the University of Michigan.

\section{References}

Beltrami, H., A. M. Jessop, and J.-C. Mareschal, Ground temperature histories in eastern and central Canada from geothermal measurements: Evidence of climatic change, Palaeogeogr. Palaeoclimatol. Palaeoecol., 98, 167-184, 1992.

Beltrami, H., L. Z. Cheng, and J.-C. Mareschal, Simultaneous inversion of borehole temperature data for past climate determination, Geophys. J. Int., 129, 311-318, 1997.

Bodri, L., and V. Cermak, Climate changes of the last millennium inferred from borehole temperatures: Results from the Czech Republic, part 1, Global Planet. Change, 11, 111-125, 1995.

Briffa, K. R., F. H. Schweingruber, P. D. Jones, T. J. Osborn, S. G. Shiyatov, and E. A. Vaganov, Reduced sensitivity of recent tree-growth to temperature at high northern latitudes, Nature, 391, 678-682, 1998.

Briffa, K. R., T. J. Osborn, F. H. Schweingruber, I. C. Harris, P. D. Jones, S. G. Shiyatov, and E. A. Vaganov, Low-frequency temperature variations from a northern tree ring density network, J. Geophys. Res., 106, 2929-2941, 2001.

Cohen, J., K. Saito, and D. Entekhabi, The role of the Siberian high in Northern Hemisphere climate variability, Geophys. Res. Lett., 28(2), 299-302, 2001. 
Cooper, G. R. J., and M. Q. W. Jones, Optimized inversion of borehole temperature data, Geophysics, 63, 331-336, 1998

Demezhko, D. Y., Geothermal Method for Paleoclimate Reconstruction (Examples From the Urals, Russia) (in Russian), 143 pp., Russ. Acad. of Sci., Urals Branch, Ekaterinburg, Russia, 2001.

Duchkov, A. D., and H. N. Pollack, Century-long climate change trends in historical time reconstructed from borehole temperatures, Earth Cryosphere, 6(1), 82-89, 2002.

Duchkov, A. D., and L. S. Sokolova, Investigation of temperature changes at the Earth's surface via borehole geothermometry, in Problems of climatic reconstruction and environment of the Holocene and the Pleistocene in Siberia (in Russian), pp. 151-157, vol. 1, Nauka, Novosibirsk, Russia, 1998.

Duchkov, A. D., A. A. Duchkov, and K. V. Sukhorukova, Numerical estimation of historical surface temperature in south Siberia using geothermal data (in Russian), in Problems of Climatic Reconstruction and Environment of the Holocene and the Pleistocene in Siberia, vol. 2, pp. 199-207, Nauka, Novosibirsk, Russia, 2000.

Duchkov, A. D., A. A. Duchkov, and S. G. Morozov, Century-long climate change trends of surface temperature in Altai-Sayan region by thermograms from boreholes, in The Basic Rules of Global and Regional Changes of Climate and Natural Environment in the Late Cenozoic in Siberia (in Russian), vol. 1, pp. 178-182, Inst. of Archeol. and Ethnolgr., Siberian Branch, Russ. Acad. of Sci., Novosibirsk, Russia, 2002.

Esper, J., E. R. Cook, and F. H. Schweingruber, Low frequency signals in long tree-ring chronologies for reconstructing past temperature variability, Science, 295, 2250-2253, 2002.

Golovanova, I. V., R. N. Harris, G. V. Selezniova, and P. Stulc, Evidence of climatic warming in the southern Urals region derived from borehole temperatures and meteorological data, Global Planet. Change, 29, $167-188,2001$.

Grove, J. M., The Little Ice Age, 498 pp., Methuen, New York, 1988.

Huang, S., and H. N. Pollack, Global borehole temperature database for climate reconstruction, Contrib. Ser. 1998-044, IGBP PAGES/World Data Cent.-A for Paleoclimatol. Data, NOAA/NGDC Paleoclimatol. Program, Boulder, Colo., 1998.

Huang, S., P.-Y. Shen, and H. N. Pollack, Deriving century-long trends of surface temperature from borehole temperatures, Geophys. Res. Lett., 23(3), 257-260, 1996

Huang, S., H. N. Pollack, and P.-Y. Shen, Temperature trends over the last five centuries reconstructed from borehole temperatures, Nature, 403 , 756-758, 2000

Jones, P. D., D. E. Parker, T. J. Osborn, and K. R. Briffa, Global and hemispheric temperature anomalies-Land and marine instrument records, in Trends: A Compendium of Data on Global Change, Carbon Dioxide Inf. Anal. Cent., Oak Ridge Natil. Lab., U.S. Dep. of Energy, Oak Ridge, Tenn., 1999a.

Jones, P. D., M. New, D. E. Parker, S. Martin, and I. G. Rigor, Surface air temperature and its changes over the past 150 years, Rev. Geophys., 37(2), 173-199, 1999b.

Kennedy, P. L., A. D. Woodbury, and K. Wang, Minimum relative entropy: Theory and application to surface temperature reconstruction from borehole temperature measurements, Geophys. Res. Lett., 27(19), 30813085, 2000.

Khachai, Y. V., D. Y. Demezhko, D. G. Ryvkin, and V. A. Shchapov, Paleotemperature reconstructions for the northern Urals according to borehole thermometry, Russ. Geol. Geophys., 37(12), 100-105, 1996.

Klimovsky, I. V., and S. P. Gotovtsev, Cryolithozone of the Yakutian diamond province, report, 98 pp., Nauka, Novosibirsk, Russia, 1994.

Lachenbruch, A. H., and B. V. Marshall, Climate change: Geothermal evidence from permafrost in the Alaskan Arctic, Science, 234, 689$696,1986$.

Lubimova, E. A., Thermal history of the Earth with consideration of the variable thermal conductivity in the mantle, Geophys. J., 1, 115-134, 1958.

Lubimova, E. A., R. P. Von Herzen, and G. B. Udintsev, On heat transfer through the ocean floor, in Terrestrial Heat Flow, Geophys. Monogr. Ser, vol. 8, edited by W. H. K. Lee, AGU, Washington, D. C., 1965.
Magnuson, J. J., et al., Historical trends in lake and river ice cover in the Northern Hemisphere, Science, 289, 1743-1746, 2000.

Mareschal, J.-C., and H. Beltrami, Evidence for recent warming from perturbed geothermal gradients: Examples from eastern Canada, Clim. Dyn., 6, 135-143, 1992.

Osterkamp, T. E., and V. E. Romanovsky, Characteristics of changing permafrost temperatures in the Alaskan Arctic, Arctic Alpine Res., 28(3), 267-273, 1996

Overpeck, J., et al., Arctic environmental change of the last four centuries, Science, 278, 1251-1256, 1997.

Pavlov, A. V., Current changes of climate and permafrost in the Arctic and sub-Arctic of Russia, Permafrost Periglacial Proc., 5(2), 101-110, 1994.

Pavlov, A. V., Permafrost climatic monitoring of Russia: Analysis of field data and forecast, Polar Geog., 20, 44-64, 1996

Pollack, H. N., and S. Huang, Climate reconstruction from subsurface temperatures, Annu. Rev. Earth Planet. Sci., 28, 339-365, 2000.

Pollack, H. N., S. J. Hurter, and J. R. Johnson, Heat loss from the Earth's interior: Analysis of the global data set, Rev. Geophys., 31(3), 267-280, 1993.

Pollack, H. N., P.-Y. Shen, and S. Huang, Inference of ground surface temperature history from subsurface temperature data: Interpreting ensembles of borehole logs, Pure Appl. Geophys., 147, 537-550, 1996.

Polyak, B. G., and Y. B. Smirnov, Relationship between terrestrial heat flow and the tectonics of continents, Geotectonics, 4, 205-213, 1968.

Serreze, M. C., et al., Observational evidence of recent change in the northern high-latitude environment, Clim. Change, 46, 159-207, 2000.

Shen, P.-Y., and A. E. Beck, Least squares inversion of borehole temperature measurements in functional space, J. Geophys. Res., 96, 19,96519,979, 1991

Shiyatov, S. G., Dendrochronology of the Upper Border of the Forest in the Urals (in Russian), 136 pp., Nauka, Moscow, 1986.

Stulc, P., I. V. Golovanova, and G. V. Selezniova, Climate change in the Urals, Russia, inferred from borehole temperature data, Stud. Geophys. Geod., 41, 225-246, 1997.

Stulc, P., I. V. Golovanova, and G. V. Selezniova, Climate change record in the Earth-Example of borehole data analysis in the Urals region, Russia, Phys. Chem. Earth, 23(9-10), 1109-1114, 1998.

Sukhorukova, K. V., and A. A. Duchkov, Reconstruction of the ground surface temperature in the last centuries by thermograms for the SouthSiberian boreholes, Russ. Geol. Geophys., 39, 1121-1129, 1998.

Vaganov, E. A., and S. G. Shiyatov, Dendrochronological methods in the study of the climate history of Siberia, in Problems of Climatic Reconstruction and Environment of the Holocene and the Pleistocene in Siberia (in Russian), edited by E. A. Vaganov et al., pp. 56-63, Nauka, Novosibirsk, Russia, 1998.

Vaganov, E. A., S. G. Shiyatov, and V. S. Mazepa, Dendroclimatic Study in Ural-Siberian Subarctic (in Russian), 245 pp., Nauka, Novosibirsk, Russia, 1996.

Wang, K., Estimation of ground surface temperatures from borehole temperature data, J. Geophys. Res., 97, 2095-2106, 1992.

Zhang, T., Climate, seasonal snow cover and permafrost temperatures in Alaska north of the Brooks range, Ph.D. thesis, University of Alaska, Fairbanks, 1993.

Zhang, T., R. G. Barry, D. Gilichinsky, S. S. Bykhovets, V. A. Sorokovikov, and J. Ye, An amplified signal of climatic change in soil temperatures during the last century at Irkutsk, Russia, Clim. Change, 49, 41-76, 2001.

S. Huang, H. N. Pollack, and J. E. Smerdon, Department of Geological Sciences, University of Michigan, Ann Arbor, MI 48109-1063, USA. (shaopeng@umich.edu; hpollack@geo.lsa.umich.edu; jsmerdon@umich. edu)

D. Y. Demezhko and V. A. Shchapov, Institute of Geophysics, Russian Academy of Sciences, Ekaterinburg, Russia. (ddem@igeoph.mplik.ru)

A. D. Duchkov, Institute of Geophysics, Russian Academy of Sciences, Novosibirsk, Russia. (duch@uiggm.nsc.ru)

I. V. Golovanova, Institute of Geology, Russian Academy of Sciences, Ufa, Russia. (golovanova@anrb.ru) 